\title{
KARAKTERISTIK TANAH LIAT DAN PENGARUHNYA TERHADAP KEBERHASILAN WARNA GLASIR
}

\author{
Prima Yustana *)
}

\begin{abstract}
This eksperiment attempts to solve common problems faced in ceramic finish, finishing ceramic objects have differences to resolve other matters. Glaze is a type of glass coating that is applied to coat the ceramic objects, this is an interesting layer to be studied, because the success glaze applications in ceramics is influenced by many factors. Applications glaze on ceramic objects have a very high level of difficulty, the difficulty seen in glaze formulas, application techniques, firing temperature, shrinkage of dry matter and the successful achievement of color after glaze the combustion process. This research is to determine whether the clay character has an influence on the success rate of the color will appear. The problem solving method uses the experimental method, this method is considered more appropriate to determine the level of success of an experiment relating to material containing chemical elements.

Clay used is a type of stoneware clay has five classes of characters, clay are as follows: 1. Pacitan soil, wet soil has a reddish color, 2. Singkawang soil, wet soil has a whitish colour, 3. Sukabumi is a brightly colored ground, wet floor is a beige, with 4. Sukabumi, the dark ground, wet soil has a dark brown color, 5. Bojonegoro soil, wet soil has a light brown color. color Glaze five characters shall be applied on the surface of clay are: 1. young Greens, 2. Pink, 3. Greenish blue, 4. Brown 5. Dark blue.

Character clay is relatively large contribution to the emergence of color glaze in accordance with the wishes or the plan, especially when using a formula based on the glossy glaze. Glaze formula will tend to be stable when there is a combination of stain with a glaze oxide, stable formula can also be found on the matt glaze, because it glaze was close or not transparent. coloring oxides are very sensitive to the character of soil temperature change is cobalt and fe,experiment that required in advance if the formula contains two types of oxide glaze. Burning with the reduction or oxidation also will give effect to the glaze colors will appear.
\end{abstract}

Keyword: experiment, color glaze, characters clay.

\section{Latar Belakang}

Sebagai bagian dari sebuah karya seni keramik, glasir memiliki peranan yang sangat penting sebagai penunjang estetika karya. Sebagaimana diketahui bahwa unsurunsur rupa terdiri dari unsur garis, unsur shape (bangun), unsur texture (rasa permukaan bahan), unsur warna, ruang dan waktu. Unsur warna merupakan salah satu medium seni rupa, warna merupakan unsur susun yang sangat penting, baik di bidang seni murni maupun seni terapan. Bahkan lebih jauh dari pada itu warna sangat berperan dalam segala aspek kehidupan manusia. Hal ini dapat dilihat dari berbagai benda atau peralatan yang digunakan oleh manusia yang selalu diperindah dengan penggunaan warna; mulai dari pakaian, perhiasan, peralatan rumah tangga, dari barang kebutuhan sehari-hari sampai barang yang eksklusif semua memperhitungkan kehadiran warna (Dharsono, 2007: 76).

*) Prima Yustana (pyprim@gmail.com), Staf Pengajar Program Studi Kriya Seni, Jurusan kriya, Fakultas Seni Rupa, Institut Seni Indonesia Surakarta. 
Pentingnya warna sudah tidak diragukan lagi, apabila diterapkan dalam karya keramik, warna juga akan sangat mempengaruhi kualitas karya seni keramik tersebut. Warna dalam keramik biasanya muncul dari karakteristik tanah liat atau dari unsur pewarna kimia yang berupa pigmen/stain glasir atau oksida besi yang diaplikasikan ke dalam formula glasir. Glasir adalah suatu macam gelas khusus yang diformulasikan secara kimia, agar melekat pada permukaan tanah liat, atau melebur ke dalam badan waktu dibakar. Kebanyakan pot/wadah fungsional diglasir untuk membuatnya tidak tembus air, awet, dan mudah dibersihkan. Glasir dapat berwarna atau menutup dan sangat efektif bila digunakan sebagai dekorasi (Ambar Astuti, 1997: 91).

Penguasaan teknik mengglasir harus dimiliki setiap seniman atau kriyawan yang akan menekuni tentang seni keramik, menurut Subroto teknologi keramik termasuk yang paling rumit dibandingkan dengan cabang-cabang seni lainnya. Di samping itu, keramik memerlukan proses panjang dalam penciptaannya. Masingmasing tahap, sejak awal hingga akhir sangat berkaitan erat. Dikatakan juga bahwa bila ingin maju, maka pengembangan keramik harus sampai ke tingkat keramik berglasir dan bersuhu tinggi, tetapi hal tersebut harus berbanding lurus dengan adanya tungku dan bahan-bahan glasirnya (Soedarso, 1991: 197).

Bentuk eksperimen yang akan dilakukan adalah dengan membuat potongan-potongan tanah liat dengan ukuran tertentu sejumlah 25 buah yang akan diukur penyusutan tanah liat ketika masih basah dan kering. Pengukuran penyusutan juga dilakukan ketika setelah dilakukan proses pembakaran pertama (biscuit) dan setelah pembakaran kedua (bakar glasir), kemudian formula glasir yang terdiri dari 5 macam warna glasir dengan pewarna oksida diaplikasikan pada potongan tanah liat yang telah melalui proses tes susut basah dan kering serta susut setelah bakar biskuit.

Potongan-potongan tanah liat yang telah melalui proses pengukuran sampai bakar pertama (biskuit) kemudian dilanjutkan dengan mengaplikasikan formula glasir pada permukaan potongan-potongan tanah liat yang telah dibakar biskuit. Pembakaran glasir akan diusahakan menuju pada tingkatan suhu tertentu yang akan dicapai merata pada semua potongan karakter tanah liat. Warna akan dapat dilihat setelah proses bakar glasir selesai dilakukan, sehingga akan dapat diketahui berbagai macam pengaruh karakter tanah liat dengan warna glasir yang akan terwujud. Ada beberapa permasalahan yang menarik untuk dikaji yaitu 1) Faktor apa saja yang dapat menentukan ketepatan munculnya warna glasir?; 2) Apakah karakter tanah begitu menentukan tingkat keberhasilan munculnya warna glasir?; 3) Apakah ada cara yang mudah dan tepat agar warna glasir muncul sesuai dengan keinginan?

Ada hal-hal penting dan bermanfaat terkait dengan beberapa pihak yang baik secara langsung maupun tidak langsung terhadap hasil kajian ini. Hal-hal tersebut adalah 1) Sebagai pedoman bagi para pengrajin atau seniman yang akan membuat karya keramik yang berglasir; 2) Sebagai sarana untuk meningkatkan ketrampilan dalam penguasaan glasir; 3) Memberikan sumbangan pemikiran dan analisis faktual kepada semua pihak yang ingin mengembangkan seni keramik secara professional; 4) Memberikan pengembangan dalam pewarnaan glasir, agar dapat memacu kreativitas seniman maupun pengrajin dalam mengkombinasi warna glasir; 5) Sebagai salah satu bentuk aktualisasi kajian eksperimen ilmiah tentang aspek teknis yang sangat penting dalam mencapai kesempurnaan pembuatan karya seni keramik. 


\section{Awal Perkembangan Keramik di Indonesia}

Keramik merupakan seni kerajinan yang banyak mengalami perkembangan dan perubahan, hal ini dapat dilihat dari awal mula munculnya seni keramik di Indonesia. Pada awalnya benda keramik hanya dianggap sebagai benda kerajinan, bukan benda seni rupa. Seniman-seniman muda dengan semangat baru mulai ingin memakai bahan tanah liat sebagai media ekspresi pribadi. Percobaan pertama yang dibuat adalah dalam bentuk karya patung, percobaan-percobaan yang tidak terencana tersebut dilakukan di Bandung, Jawa Barat dan Yogyakarta oleh para mahasiswa. Hasil percobaan dari mahasiswa tersebut hanya berarti sebagai benda yang menyenangkan karena bersifat dekoratif, munculnya sekolah tinggi seni rupa di Indonesia juga sangat membantu perkembangan seni keramik Indonesia modern (Mochtar Kusuma Atmadja,1990-1991: 156).

Fakultas Seni Rupa dari Institut Teknologi Bandung (ITB) adalah institusi pertama yang menyelenggarakan program seni keramik pada tahun 1963. Dalam lingkungan seni rupa modern Indonesia, seni rupa keramik tidak dapat berkembang dengan lancar. Bidang ini sangat baru sehingga para seniman ragu dan berhati-hati dalam mengembangkan seni keramik. Kesulitan teknis, maupun kesulitan gagasan dihadapi karena masyarakat Indonesia hanya sempat mengenal keramik sebagai hasil kerajinan tradisional yang dihasilkan oleh para tukang. Teknik-teknik mengglasir dan pembakaran dengan suhu tinggi untuk menciptakan seni keramik kontemporer belumlah dikuasai oleh seniman Indonesia. Pada dasarnya perkembangan seni keramik modern di Indonesia dapat dibagi dalam empat periode, pertama adalah periode eksplorasi pada sebelum tahun 1960, kedua adalah periode akademis, yakni pada tahun 1963 sampai 1970, ketiga adalah periode pertumbuhan yakni pada tahun 1975-1985, dan yang keempat adalah periode munculnya seniman-perajin pada tahun 1985 sampai sekarang (Mochtar Kusuma Atmadja, 1990-1991: 157-160)

\section{Pengertian Keramik}

Pengertian keramik apabila merujuk dari pendapat Ambar Astuti adalah kata keramik berasal dari bahasa Yunani "keramos" yang berarti periuk atau belanga yang dibuat dari tanah. Sedang yang dimaksud dengan barang/bahan keramik ialah: semua barang/bahan yang dibuat dari bahan-bahan tanah/batuan silikat dan yang proses pembuatannya melalui pembakaran pada suhu tinggi (Ambar Astuti, 1997: 1).

Benda keramik dapat dipahami sebagai sebuah benda yang proses pembuatannya dibuat dengan menggunakan tanah atau batuan silikat dengan melalui proses pembakaran dengan suhu tinggi. Suhu yang tinggi menurut penjelasan tersebut menjadi syarat mutlak bahwa benda tersebut akan disebut keramik atau bukan.

Eropa bukan yang pertama mengembangkan keramik, sebenarnya Tiongkoklah negeri asal tempat membuat barang-barang keramik, jauh sebelum Nabi Isa lahir yaitu kira-kira 206 tahun sebelum tahun masehi. Barang-barang yang dibuat oleh negeri Tiongkok (sekarang China) antara lain adalah guci untuk menyimpan anggur. Guci yang dibuat pada saat itu belum menggunakan glasir, karena waktu itu belum dikenal glasir. Pada tahun 220 baru dibuat gerabah dengan menggunakan glasir, gerabah yang dibuat adalah barang keramik yang keras berwarna dan glasir yang digunakan adalah glasir timbal (timah hitam (R.A. Razak, 1993: 6).

Pada zaman dinasti Han, yaitu abad VIII sampai dinasti T'ang pada abad $X$, keramik di Tiongkok / China berkembang dengan pesat. Pada abad $\mathrm{X}$ dalam dinasti Song dibuat barang-barang porselen yang halus, putih murni dan biru putih yang masih digemari orang sampai sekarang ini. Pada abad XVII barang-barang keramik 
berkembang dengan pesat, baik kwantum maupun mutunya, sehingga pada zaman dinasti Ming banyak sekali barang-barang tersebut terutama porselen biru-putih diekspor ke negara-negara Eropa dan Asia. Pada zaman itulah banyak negara-negara Eropa dan Asia meniru membuat barangbarang porselen (R.A. Razak, 1993: 6).

Pada abad itu Keramos dari Yunani mulai membuat barang-barang keramik, sehingga nama keramik sejak abad itu dikenal sampai sekarang. Demikian juga Jepang pada abad XVII mulai membuat barang-barang keramik. Masyarakat pembuat keramik di Jepang belajar langsung dari orang-orang Tiongkok, kemudian muncullah nama Satsuma yang tersohor pada abad XVIII sampai XX dan nama Sino Yapanico sebagai peniru barang- barang keramik biru-putih dari Tiongkok. Perkembangan produsen keramik diantara negara-negara yang telah maju, Jepanglah sekarang yang mewakili Asia, karena sudah jauh lebih maju teknologinya daripada Tiongkok sendiri (R.A. Razak, 1993: 6-7).

\section{Pengertian Tanah Liat.}

Tanah liat adalah bahan utama untuk pembuatan keramik, tanah liat merupakan suatu zat yang terbentuk dari kristal-kristal yang kebanyakan sedemikian kecilnya hingga tidak dapat dilihat walaupun telah menggunakan mikroskop biasa yang bagaimanpun kuatnya. Kristal-kristal ini terbentuk dari mineral-mineral yang disebut kaolinit. Bentuknya seperti lempengan kecilkecil hampir berbentuk segi enam dengan permukaan yang datar. Bentuk kristal-kristal seperti itu menyebabkan tanah liat bila dicampur dengan air mempunyai sifat liat (plastis), sehingga mudah dibentuk karena kristal-kristal ini meluncur di atas satu dengan yang lainnya dengan air sebagai pelumasnya (Ambar Astuti, 1997:13).

Unsur kimia tanah liat termasuk hidrosilikat alumina dan dalam keadaan murni mempunyai rumus: $\mathrm{Al}_{2} \mathrm{O}_{3} \quad 2 \mathrm{SiO}_{2} \quad 2 \mathrm{H}_{2} \mathrm{O}$ dengan perbandingan berat dari unsur- unsurnya: $47 \%$ oksida Silinium $\left(\mathrm{SiO}_{2}\right), 39 \%$ oksida Aluminium $\left(\mathrm{Al}_{2} \mathrm{O}_{3}\right)$, dan $14 \%$ air $\left(\mathrm{H}_{2} \mathrm{O}\right)$ (Ambar Astuti, 1997:13), Rumus tersebut lebih dapat mejelaskan secara ilmiah kenapa tanah liat memiliki sifat yang plastis atau mudah dibentuk dan apabila dilakukan pembakaran akan menjadi keras.

\section{Pengertian Glasir}

Pengertian glasir menurut Greg Daly glasir adalah lapisan kaca tipis yang telah menyatu pada permukaan badan keramik. Dalam ketentuan sederhana komposisi glasir memiliki tiga bagian yaitu:

1) Silica, $\mathrm{SiO}_{2}$, sebagai pembentuk kaca pada saat meleleh (permasalahannya adalah titik leburnya sekitar $1710^{\circ} \mathrm{C}$ atau $3110^{\circ} \mathrm{F}$; 2) Flux, digunakan sebagai penurun suhu titik lebur dari silica; 3) Alumina, $\mathrm{Al}_{2} \mathrm{O}_{3}$, berfungsi sebagai penambah daya rekat dari glasir dan digunakan sebagai penyeimbang di permukaan benda (untuk menghentikan glasir meleleh dengan cepat); alumina membuat glasir lebih dapat menjangkau suhu pembakaran. Sebagian mungkin menyamakan alumina sebagai tepung di dalam komposisi. Kandungan alumina dalam jumlah yang tinggi akan membuat karakter glasir berbeda dengan jenis kaca jendela (Greg Daly, 1995: 7).

R.A. Razak mengemukakan pengertian glasirnya yang tidak jauh dari pendapat Greg Daly, namun pendapatnya akan lebih melengkapi pengertian glasir yang ada yakni glasir adalah lapisan tipis bahanbahan silikat pada permukaan barang-barang keramik, yang lebur setelah dibakar dan merupakan selaput gelas tipis. Glasir membuat barang-barang tidak dapat ditembus oleh gas maupun cairan, dan membuat barang-barang tambah kuat dan indah. Sifat-sifat kimia dan alamiah glasir sama dengan gelas. Perbedaannya dari gelas biasanya ialah mengenai kadar oksida aluminanya. Pada gelas biasa oksida alumina termasuk bahan ketidak murnian sedang glasir oksida (alumina) itu merupakan salah 
satu bahan yang penting (R.A. Razak, 1993: 153).

Menurut R.A. Razak jenis-jenis glasir meliputi 1) Glasir transparan, glasir penutup, glasir kusam dan glasir berwarna; 2) Glasir timbal dan glasir yang tidak mengandung timbal; 3)Glasir yang di frit dan glasir yang tidak di frit; 4) Glasir untuk gerabah putih, glasir untuk stoneware atau keramik keras berwarna, glasir porselen lunak, dan glasir porselen keras.

\section{Pembakaran}

Mengacu pendapat Ambar Astuti, tahap ini merupakan bagian yang paling kritis dalam proses pembuatan barang-barang keramik. Proses pembakaran adalah proses penentuan, bila barang keramik rusak/pecah dalam pembakaran maka barang-barang tersebut tidak dapat diperbaiki lagi. Kesalahan yang terjadi pada proses sebelumnya kadang tidak terlihat, tetapi setelah melalui proses pembakaran kesalahan-kesalahan tersebut akan muncul dan terlihat.

Pembakaran barang keramik dapat dilakukan dalam tiga tingkatan yaitu pembakaran barang tidak berglasir (bakar biskuit), pembakaran barang dengan lapisan glasir (bakar glasir), dan pembakaran barangbarang yang sudah diglasir untuk membuat dekorasi (bakar dekorasi atau bakar overglaze). Pembakaran biskuit biasanya dilakukan sekedar untuk memberikan kekokohan pada benda untuk memudahkan pekerjaan selanjutnya. Kadang-kadang bakar biskuit juga dilakukan pada suhu tinggi sesuai dengan keperluan membakar barang hingga matang, kemudian setelah dibakar biskuit tinggi barang-barang dapat dibakar lagi dengan glasir pada suhu rendah.

Ambar Astuti menggolongkan beberapa tahapan pembakaran keramik (Ambar Astuti, 1997: 58-60) sebagai berikut: 1) Pembakaran biscuit, pembakaran biskuit yaitu barang keramik yang dibakar pertama kali dengan suhu bakar di bawah $1.000{ }^{\circ} \mathrm{C}$, pada suhu tersebut barang menjadi keras, kuat, tidak hancur oleh air dan juga dapat menghasilkan warna; 2) Pembakaran glasir, pembakaran glasir yaitu barang keramik bakar biskuit yang dilapisi dengan bahan glasir dan dibakar pada suhu yang dibutuhkan untuk mematangkan bahan glasirnya, sehingga barang tersebut tidak tembus air. Suhu untuk pembakaran glasir bermacam-macam, dari $980{ }^{\circ} \mathrm{C}$ sampai di atas $1.250{ }^{\circ} \mathrm{C}$ tergantung dari jenis tanah /badan dan jenis glasir yang dipakai; 3) Pembakaran barang untuk overglaze decoration, dibutuhkan suhu bakar antara $700{ }^{\circ} \mathrm{C}-900{ }^{\circ} \mathrm{C}$, dalam pembakaran golongan ke-3 ini barang keramik telah dibakar glasir, kemudian bahan overglaze diterapkan pada badan berglasir tersebut dengan media minyak khusus. barang tersebut kemudian dibakar dengan suhu rendah. Pembakaran benda keramik merupakan suatu hal yang penting dan sangat menentukan dalam seluruh proses pembentukannya.

Perkembangan dan perubahan keadaan di dalam tungku pembakaran selama proses pembakaran berlangsung akan terjadi beberapa tahapan perubahan. Tahapan perubahan tersebut adalah:

a. Tahap menghilangkan uap air

Suhu pembakaran untuk tahap ini berlangsung dari awal sampai sekitar $500^{\circ} \mathrm{C}$. Tahap ini disebut penghilangan uap air karena pada saat ini air yang terikat pada molekul tanah liat (air kimia) menguap, selain itu unsur karbon dan unsur organis dibakar habis. Pembakaran pada tahap ini harus dilakukan perlahan-lahan terutama pada saat membakar barang yang berukuran besar, dengan maksud agar air dapat diuapkan melalui pori-pori benda keramik. Jika panas terlalu cepat meningkat kemungkinan uap air tidak dapat keluar segera dari pori-pori tersebut sehingga dapat menimbulkan letusan. Setelah air habis mulai pembakaran dari zat-zat organis dan karbon.

Pada suhu antara $350^{\circ} \mathrm{C}-400^{\circ} \mathrm{C}$ zatzat organis dan unsur karbon terbakar habis, 
jika pada saat ini suhu pembakaran terlalu cepat meningkat, mungkin terjadi penggelasan yang dapat menghambat pembakaran gas yang seakan-akan tertutup oleh lapisan gelas tersebut. Pada suhu $500^{\circ} \mathrm{C}$ berakhir dan mulai dengan penggelasan.

b. Tahap penggelasan/ pengerasan/ vitrivication

Suhu penggelasan dimulai dari suhu $500^{\circ} \mathrm{C}$ sampai tercapai taraf penggelasan pada suhu sekitar $800^{\circ} \mathrm{C}$. Perlu diketahui bahwa unsur pembentuk gelas akan mencair kemudian menjadi gelas dan kalau didinginkan akan menjadi keras. Pada umumnya pembakaran dalam tahap ini berlangsung lebih cepat dibanding tahap menghilangkan uap air. Apabila tanah liat banyak mengandung silica dalam bentuk pasir atau flint pembakaran harus diperlambat. Sebab dalam fase pembakaran struktur kristal silica akan berganti-ganti pada beberapa temperatur tertentu.

Pembakaran struktur yang paling menentukan adalah pada suhu $573^{\circ} \mathrm{C}$. Pada suhu ini tungku pembakaran mulai menjadi merah panas dan terjadi pergantian phisik (perubahan volume yang cepat sekali) dari silica yang membuatnya mengembang. Keadaan tersebut menyebapkan pembakaran tidak boleh terlalu cepat terutama pada benda yang berukuran besar dan banyak mengandung silica akan terjadi tekanan padanya sehingga mungkin pecah pada pergantian volume tadi. Suhu $573^{\circ} \mathrm{C}$ ini merupakan titik kritis dalam pembakaran tahap penggelasan juga dalam tahap pendinginan. Dalam tahap pendinginan struktur silica akan berubah lagi dengan cepat dan menyusut pada suhu $573^{\circ} \mathrm{C}$. Titik inilah yang disebut inverse kwarsa, pembakaran biskuit dapat dipercepat jika suhu pembakaran telah mencapai $600^{\circ} \mathrm{C}$.

c. Tahap Pendinginan

Jika suhu pembakaran telah tercapai yaitu sekitar $800^{\circ} \mathrm{C}$ dan benda keramik telah matang, maka api harus dipadamkan dan tungku dibiarkan menjadi dingin. Jika ada lubang udara pada tungku, sebaiknya lubang tersebut tidak langsung dibuka atau ditutup sebagian saja agar pendinginan diperlambat. Hal ini perlu terutama kalau benda yang dibakar besar-besar atau banyak mengandung silica dan pasir. Apabila suhu dalam tahap pendinginan telah menurun sampai pada $573^{\circ} \mathrm{C}$, maka akan terjadi lagi pergantian struktur kristal silica. Pendinginan yang diperlambat, akan menghindarkan dari benda-benda dari keretakan dan juga akan menghemat tungku, sebab bagian-bagian dalam dari tungku tersebut (terutama elemen-elemen tungku listrik) sedikitnya akan terpengaruh juga oleh perubahan suhu. Sebaiknya tungku itu dibiarkan tertutup sampai benda-benda dapat diambil dari dalam tungku dengan tangan.

\section{Tungku Pembakaran}

Pakar keramik Greg Daly menyatakan bahwa tungku sendiri memiliki pengaruh yang sangat besar terhadap kualitas glasir yang dihasilkan. Perangkat pemanas tungku memiliki bermacam jenis tergantung bahan bakar yang digunakan. Bahan bakar dapat mempengaruhi keberhasilan pembakaran glasir. Penggunaan bahan bakar kayu akan berdampak langsung pada kualitas glasir terutama ketika abu beterbangan. Abu yang dihasilkan dalam tungku pembakaran oleh api dan aliran udara yang mengenai permukaan glasir akan memberikan efek berbeda pada lokasi, tergantung pada arah api dan glasir yang dipakai.

Bahan bakar minyak akan memberikan kualitas yang berbeda, tetapi tidak begitu populer. Pembakaran yang tidak benar dengan menggunakan minyak akan menghasilkan asap hitam dan itu tidak ramah lingkungan. Kotoran dalam minyak akan bereaksi secara halus dengan glasir. Pengrajin yang terbiasa menggunakan bahan bakar minyak biasanya menemukan kenangan dengan permukaan tersebut, pada saat beralih menggunakan bahan bakar gas, banyak yang merasakan glasirnya kehilangan 
sesuatu. Gas jika dibandingkan dengan minyak akan menghasilkan udara yang bersih, juga efisien dan mudah penggunaannya serta tidak memberikan reaksi terhadap glasir sebagaimana bahan bakar kayu maupun minyak.

Pembakaran dapat dilakukan dengan bahan bakar gas, minyak, atau kayu semua bahan bakar tersebut dapat memberikan atmosfir reduksi maupun oksidasi. Apabila menggunakan tungku listrik maka atmosfir hanya akan oksidasi, tungku listrik dapat direduksi dengan menggunakan gas atau kayu, tetapi cara ini akan menyebabkan kerusakan pada elemen jika dilakukan terlalu sering.

Jenis Tungku mempunyai beberapa jenis diantaranya Tungku listrik, Tungku Gas, Tungku dengan benda padat sebagai bahan bakarnya, dan Tungku minyak.

\section{Proses Eksperimen}

\section{Alat Dan Bahan}

Alat yang digunakan dalam eksperimen meliputi:
1. Tungku pembakaran
7. Spraygun dan meja semprot,
2. Timbangan,
8. Buku catatan,
3. Mortar,
9. Masker,
10. Tali Senar, Pisau, Penggaris, Potongan lantai keramik,
4. Mangkuk plastik,
5. Saringan,
11. Kuas,
6. Kompresor listrik,
12. Amplas,
13. Spon.

Bahan yang digunakan dalam eksperimen:
1. Tanah Liat.
7. Kwarsa.
13. Glasir TSG.
2. Glasir Opag.
8. Oksida Fe.
14. Zircon.
3. Oksida Titanium.
9. Feldspar.
15. Stain merah maron.
4. Zinc oxide.
10. Whiting.
5. Barium.
11. Kaolin.
16. Gas elpiji.
6. Copper oxide.
12. Cobalt oxide.
17. Air.

Pembuatan Media dengan Lima Karakter Tanah Liat

Karakter tanah liat terdiri lima berwarna gelap, tanah liat Bojonegoro, tanah liat Pacitan, dan tanah liat Singkawang (Kalimantan). eksperimen diawali dengan macam yakni: tanah liat Sukabumi yang berwarna cerah, tanah liat Sukabumi yang pengumpulan contoh tanah liat dari berbagai daerah sejumlah lima macam:

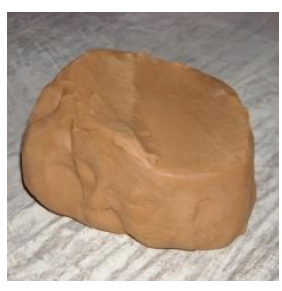

a.

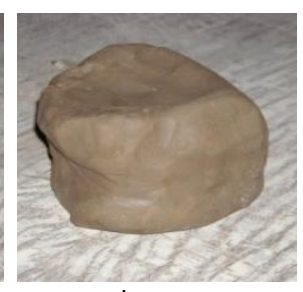

b.

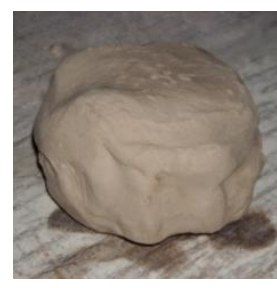

C.

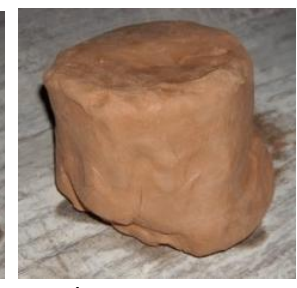

d.

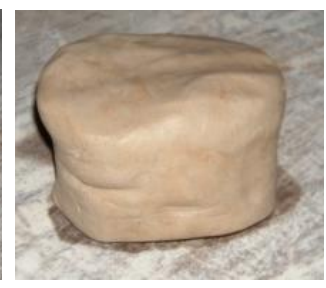

e.

Gambar 2. a. Kondisi basah tanah liat Bojonegoro, b. Kondisi basah tanah liat Sukabumi Gelap, c. Kondisi basah tanah liat Sukabumi Cerah, d. Kondisi basah tanah liat Pacitan, e. Kondisi basah tanah liat Singkawang (Kalimantan)

Kelima karakter tanah tersebut memiliki perbedaan sifat dan tampilan visualnya, Berdasarkan pengamatan di lapangan ada perbedaan-perbedaan yang sangat mencolok dari kelima tanah liat tersebut sebagai berikut: 
Keterangan Tanah liat: a) Tanah liat Bojonegoro, tanah ini memiliki warna basah coklat muda, dan akan berwarna lebih muda setelah kering, tanah liat ini memiliki tingkat keplastisan yang tinggi. Mudah dalam melakukan penguledan (homogenisasi tanah agar gelembung udara di dalam tanah hilang sehingga tanah menjadi plastis dan padat); b) Tanah liat Sukabumi Gelap, Tanah ini memiliki warna basah coklat tua, dan akan berwarna lebih muda setelah kering, tanah liat ini memiliki keplastisan yang sangat tinggi, tetapi pada saat melakukan penguledan tanah ini sedikit susah homogen karena sifatnya yang sangat plastis; c) Tanah liat Sukabumi cerah, tanah ini memiliki warna basah coklat keputih-putihan, dan akan berwarna lebih muda pada saat sudah kering. Tanah ini sangat mudah dibentuk dan sangat plastis, dalam proses penguledan juga dapat dengan mudah dilakukan; d) tanah liat Pacitan, tanah ini memiliki warna basah merah kecoklatan dan akan berwarna lebih cerah pada saat sudah kering, karakter tanah ini sangat plastis, sehingga dapat dibentuk sesuai dengan keinginan tanpa kesulitan yang berarti; e) tanah liat Singkawang (Kalimantan), tanah ini memiliki warna basah putih keabu-abuan, dan akan berwarna lebih cerah apabila dalam kondisi kering. Tanah ini memiliki karakter yang kurang plastis jadi, pada saat belum melalui proses pembakaran tanah ini sangat rawan pecah atau patah.

$$
\text { Proses selanjutnya adalah }
$$
pembuatan media eksperimen yang berupa lempeng-lempeng tes yang dengan ukuran panjang $12 \mathrm{~cm}$ dan lebar $5 \mathrm{~cm}$ sejumlah 25 buah lempengan tes.
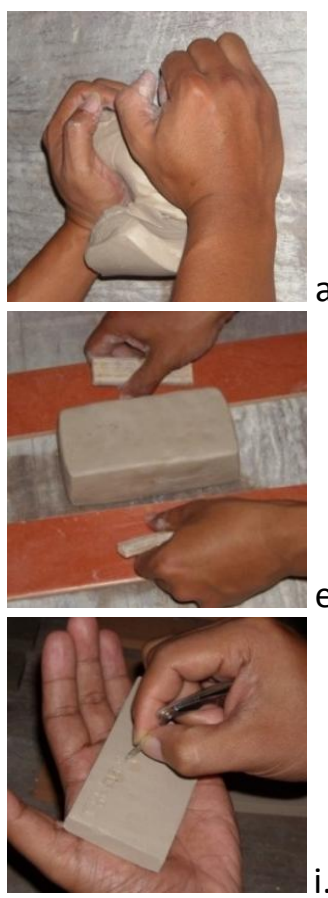

e.
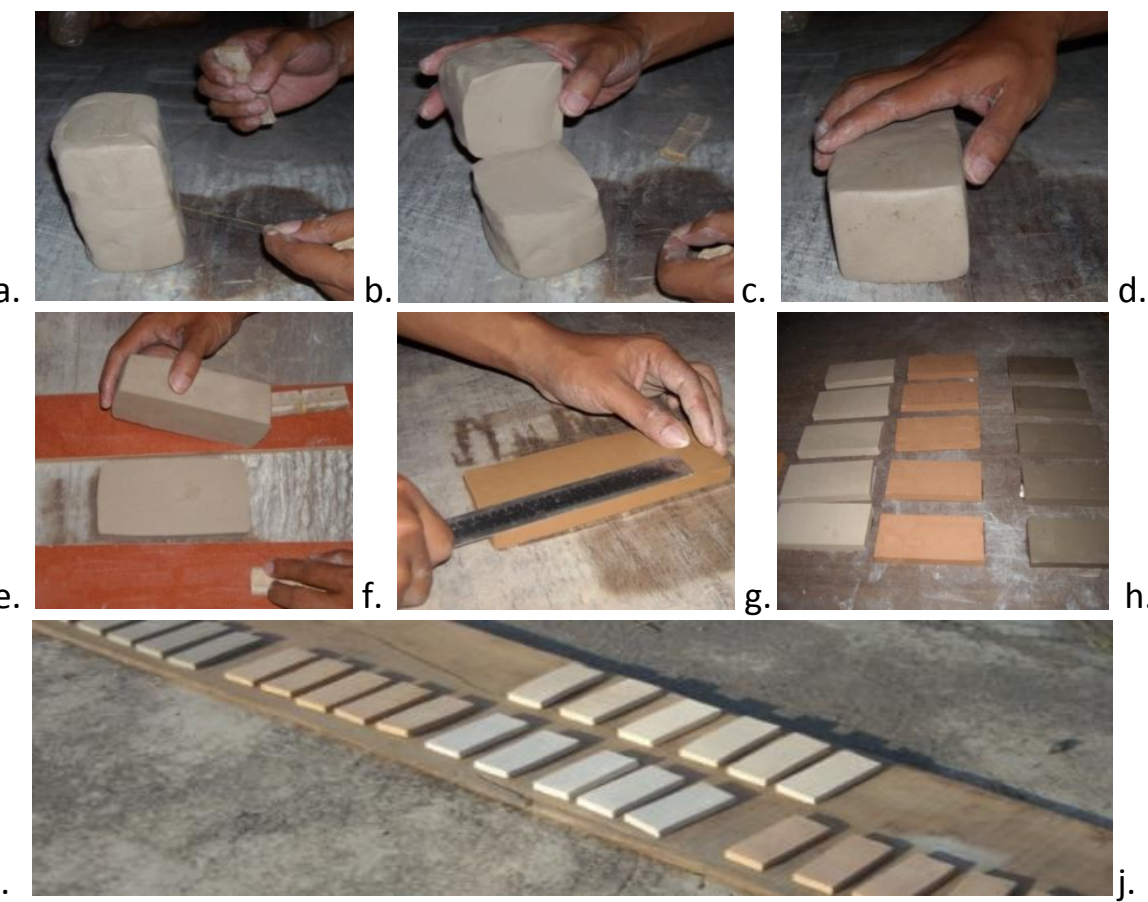

Gambar 3. media eksperimen berupa lempeng-lempeng tanah liat

Proses penguledan tanah liat agar homogen, proses ini sangat penting untuk dilakukan agar keelastisan dan kepadatan struktur tanah dapat terjadi secara merata. Gambar b menunjukkan aktivitas sedang melakukan pengecekan homogenitas tanah liat, hal ini dilakukan bertujuan untuk melihat secara langsung apakah proses penguledan sudah dirasa cukup atau belum.

Gambar c menunjukkan cara melihat apakah masih ada rongga atau gelembung udara di dalam tanah liat, apabila masih diulangi lagi proses penguledan dan pengecekan tanah sekali lagi sampai tidak 
ada rongga yang terlihat dalam potongan tanah liat. Setelah homogen tanah liat dibentuk menyerupai kotak persegi panjang, untuk memudahkan proses pemotongan seperti terlihat pada gambar $\mathbf{d}$.

Pada gambar e adalah proses pembuatan lempeng tes dengan cara memotong tanah liat yang masih berbentuk padat dengan alat bantu tali senar dam potongan keramik lantai untuk menentukan ketebalan lempeng tes agar sama tebal. Hasil potongan lempeng tes setelah diangkat, pemotongan dilakukan berulang hingga jumlah yang diharapkan terselesaikan seperti terlihat pada gambar $\mathbf{f}$.

Gambar $\mathbf{g}$ adalah proses merapikan dan mengukur lempeng percobaan dengan alat bantu penggaris agar memiliki ukuran yang sama $5 \times 12 \mathrm{~cm}$. Gambar $\mathbf{h}$ menunjukkan lempeng tes yang telah selesai dibuat.

\section{Pengeringan}

Setelah semua lempeng tes jadi kemudian didiamkan dalam suhu ruangan hingga tanah agak magel atau setengah kering, kemudian dilanjutkan proses pemberian kode tanah liat atau nama tanah liat agar mudah dalam proses identifikasi seperti pada gambar i. Langkah selanjutnya adalah pengeringan tanah pada terik sinar matahari agar tidak ada sisa air yang terkandung dalam tanah liat, sebelum masuk proses bakar pertama atau bakar biskuit terlihat pada gambar $\mathbf{j}$. Warna tanah yang tadinya basah kemudian akan mengering, akan ada perbedaan warna dari kondisi basah menjadi kondisi kering. Warna tersebut dapat dilihat pada gambar dibawah ini:

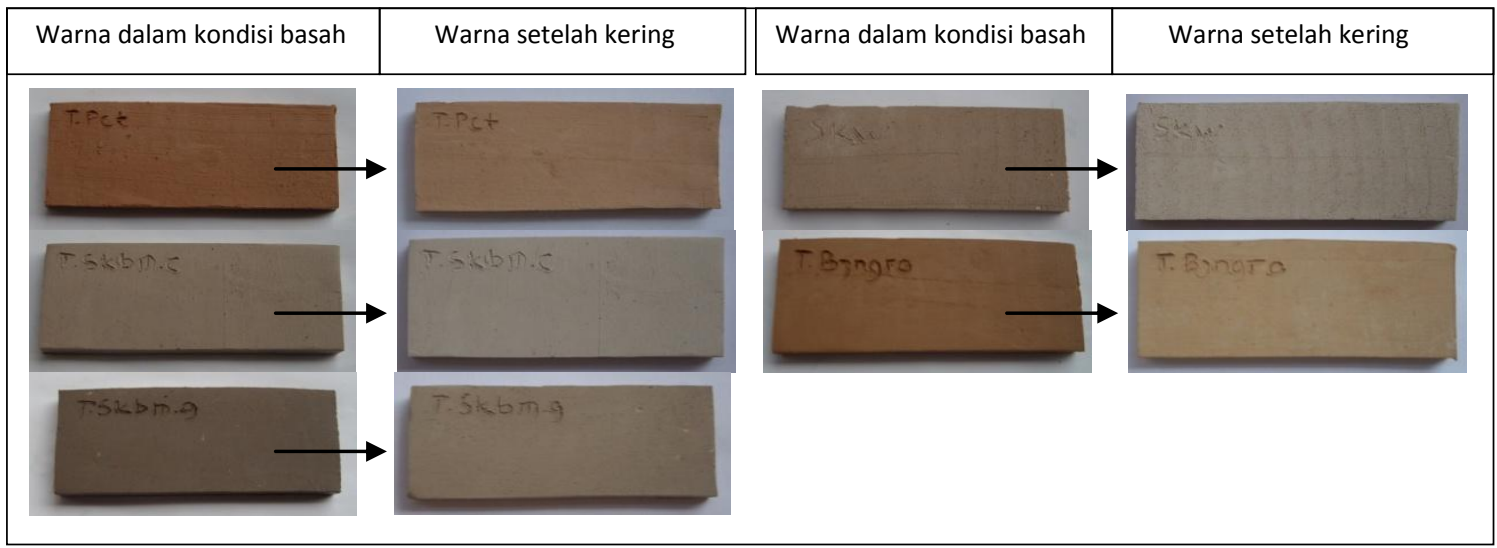

Gambar 4. Perbedaan warna tanah dalam kondisi basah dan kering

\section{Pembakaran Biskuit/Bakar I}
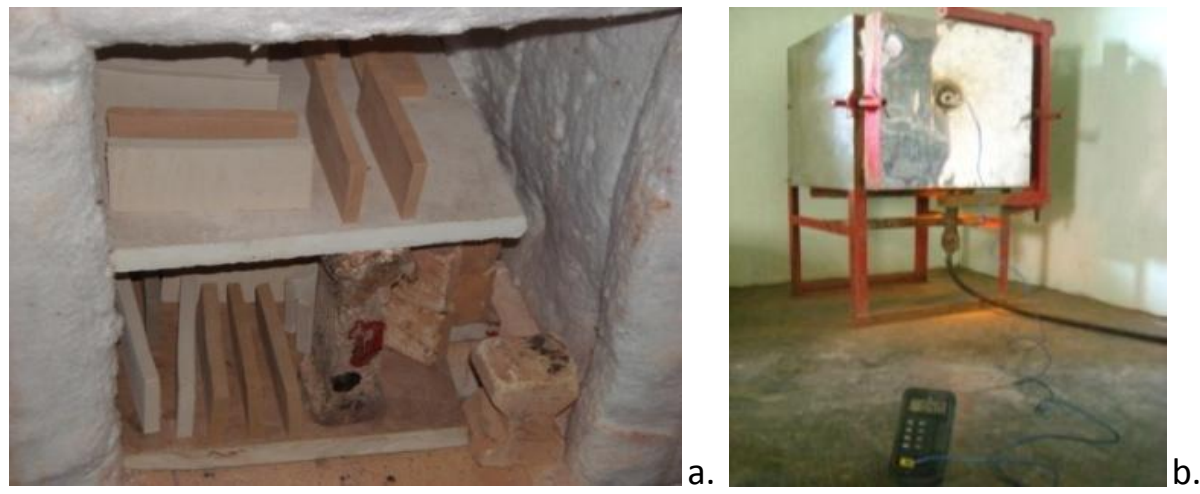

Gambar 5. a. Penataan lempeng dalam tungku, b. Tungku dengan termokoupel/alat pemantau suhu. 
Setelah kering kemudian semua lempeng tes dimasukkan ke dalam tungku pembakaran untuk dilakukan bakar pertama yakni bakar biskuit dengan suhu bakar $800^{\circ} \mathrm{C}$ dengan cara bakar oksidasi, pembakaran lempeng keramik dengan menggunakan alat pantau suhu termokoupel untuk memantau kenaikan suhu.

Setelah melalui proses pembakaran pertama atau bakar biskuit, maka kondisi tanah akan sangat berbeda sekali baik sifat maupun warnanya, kondisi tanah yang sudah dibakar biskuit strukturnya menjadi keras dan tidak hancur apabila terkena air. Sedangkan yang belum dibakar apabila terkena air maka akan dapat kembali larut dalam air. Hasil warna bakar biskuit dapat dilihat pada gambar selanjutnya:

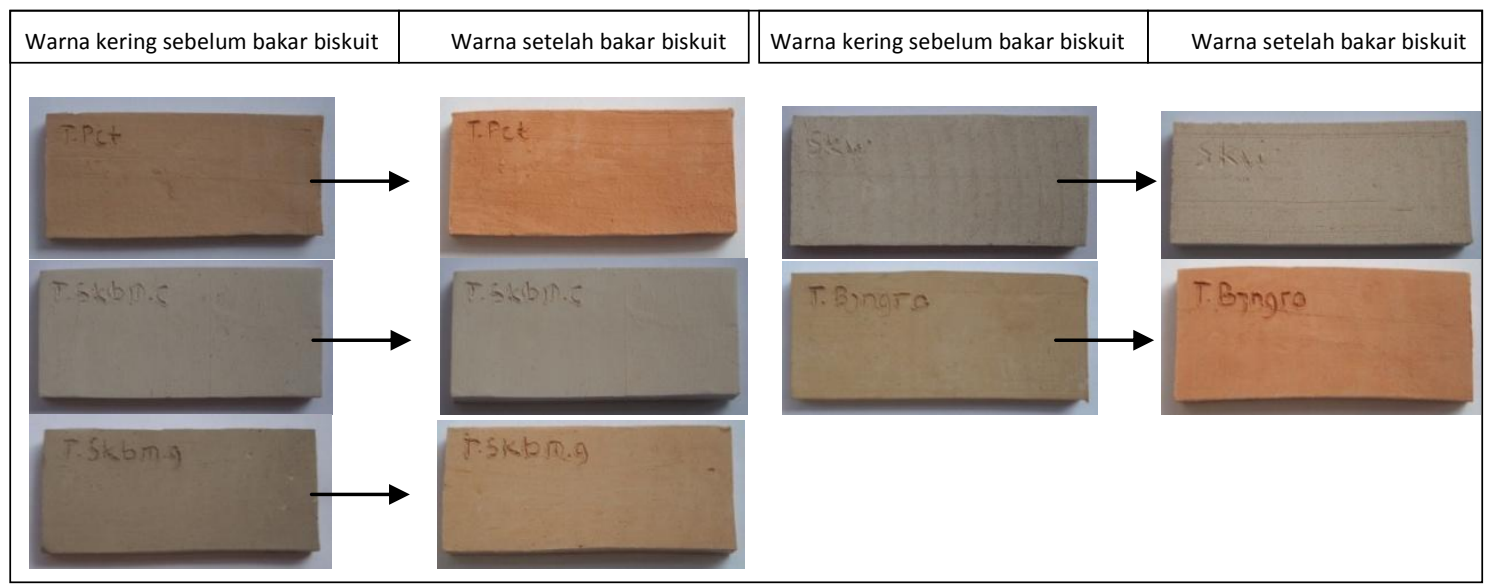

Gambar 6. Perbedaan warna tanah sebelum bakar biskuit dan warna setelah bakar biskuit

Setelah mengetahui berbagai kelebihan dan kekurangan dari kelima tanah liat tersebut maka perlu diketahui juga kelima macam warna glasir yang akan diaplikasikan di permukaan lempenglempeng eksperimen. Dalam eksperimen ini mengaplikasikan tiga jenis glasir matt atau tidak glossy dan dua macam jenis glasir glossy, Formula glasir yang direncanakan sebagai berikut:

1. Glasir dengan warna hijau muda (celadon) matt

$\begin{array}{lll}\text { - } & \text { Opag } & 100 \mathrm{gr} \\ \text { - } & \text { Titanium } & 20 \mathrm{gr} \\ \text { - } & \text { Zinc oxide } & 8 \mathrm{gr} \\ \text { - } & \text { Barium } & 1,5 \mathrm{gr} \\ \text { - } & \text { Copper oxide } & 2,5 \mathrm{gr}\end{array}$

2. Coklat Muda matt

$\begin{array}{lll}\text { - } & \text { Feldspar } & 47,5 \mathrm{gr} \\ \text { - } & \text { Whiting } & 18,6 \mathrm{gr}\end{array}$

$\begin{array}{lll}\text { - } & \text { Kaolin } & 14,6 \mathrm{gr} \\ \text { - } & \text { Zinc oxide } & 13,4 \mathrm{gr} \\ \text { - } & \text { Kwarsa } & 5,9 \mathrm{gr} \\ \text { - } & \text { Fe } & 15 \mathrm{gr}\end{array}$

3. Biru kehijauan Matt

$\begin{array}{lll}\text { - } & \text { Feldspar } & 47,5 \mathrm{gr} \\ \text { - } & \text { Whiting } & 18,6 \mathrm{gr} \\ \text { - } & \text { Kaolin } & 14,6 \mathrm{gr} \\ \text { - } & \text { Zinc oxide } & 13,4 \mathrm{gr} \\ \text { - } & \text { Kwarsa } & 5,9 \mathrm{gr} \\ \text { - } & \text { Cobalt oxide } & 0,5 \mathrm{gr} \\ \text { - } & \text { Chrom } & 1 \mathrm{gr}\end{array}$

4. Merah Muda glossy

- TSG $100 \mathrm{gr}$

- Zircon $15 \mathrm{gr}$

- Stain merah maron $6 \mathrm{gr}$

5. Biru glossy

- TSG 100gr

- Zircon $15 \mathrm{gr}$

- Cobalt oxide $3 \mathrm{gr}$ 


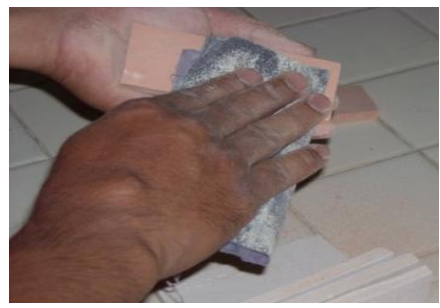

a.

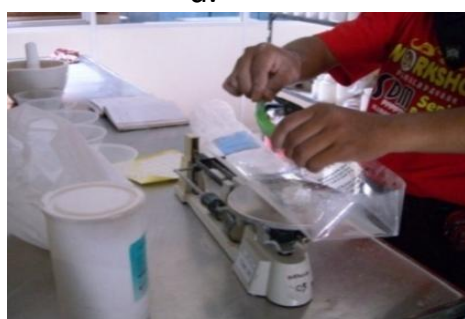

d.

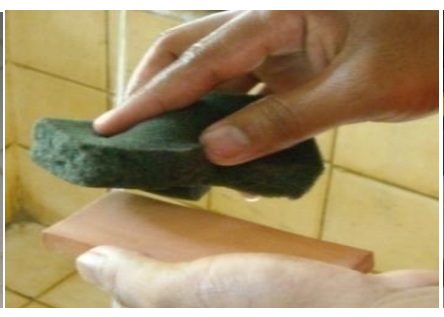

b.

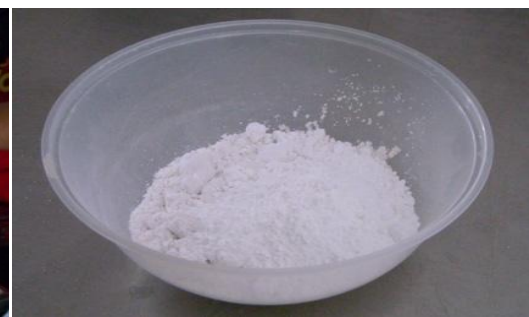

e.

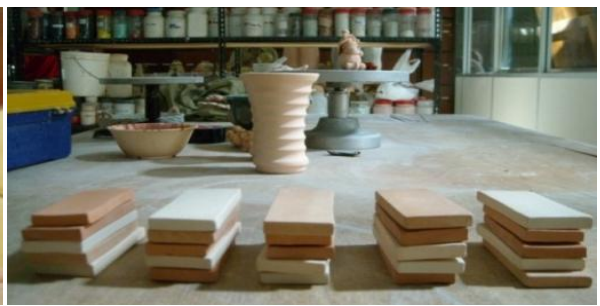

C.

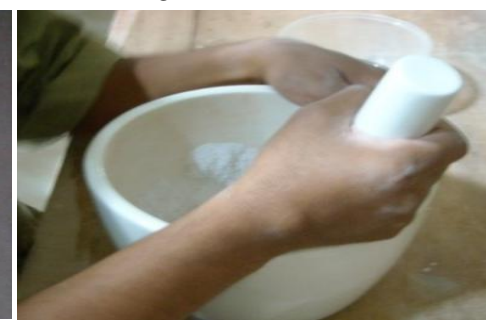

f.

Gambar 7. a. permukaan lempeng dihaluskan dengan amplas, b. Pencucian dari berbagai kotoran dan debu, c. Tumpukan lempeng dengan lima karakter tanah liat, d. Penimbangan bahan glasir, e. Satu buah formula glasir, f. Penghalusan bahan yang telah jadi menggunakan alat bantu mortal.

Setelah formula dirumuskan, tahap selanjutnya adalah membersihkan lempeng eksperimen dari berbagai kotoran dan debu, agar didapatkan permukaan yang halus dan bersih dengan menggunakan alat bantu amplas (untuk menghaluskan lempeng) dan spon (untuk mencuci lempeng).

Lempeng glasir yang telah bersih dan siap untuk diaplikasikan glasir pada permukaannya. Satu tumpukan lempeng eksperimen tersebut berisi lima macam karakter tanah liat dan masing-masing tumpukan akan diaplikasikan satu macam warna dan jenis glasir. Tahap eksperimen selanjutnya yakni mencampur dan menimbang komposisi glasir yang akan diaplikasikan pada lempeng eksperimen yang telah melalui proses bakar pertama atau bakar biskuit.
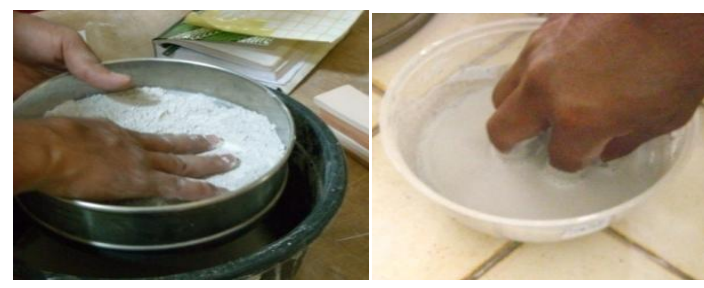

Gambar 8. Proses penyaringan bahan glasir
Proses penimbangan bahan glasir, penimbangan harus dilakukan karena setiap formula glasir yang sudah ditentukan dalam catatan harus diwujudkan sesuai masingmasing beratnya. Bahan glasir yang sudah selesai dilakukan proses penimbangan, bahan yang terdapat dalam mangkuk tersebut disebut satu buah formula glasir.

Setelah proses penimbangan bahan glasir, kemudian dilanjutkan pada proses penghalusan bahan yang telah jadi menggunakan alat bantu mortal. Apabila jumlah glasir banyak dapat menggunakan alat bantu yang disebut ball mill atau mesin penghalus glasir. Penghalusan sangat diperlukan sebab tepung glasir yang halus juga akan menentukan hasil dari permukaan glasir setelah mengalami proses pembakaran.
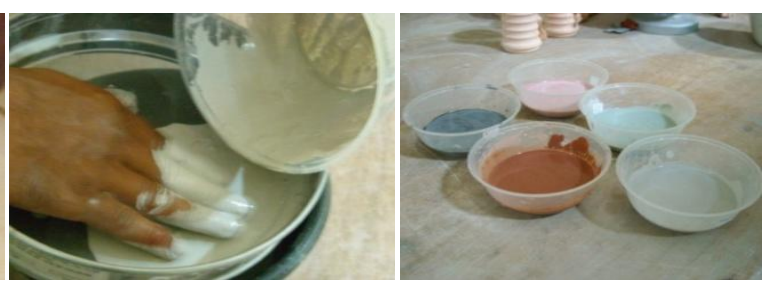
Setelah dihaluskan, tepung disaring dengan saringan khusus yang berukuran 80 mesh, ukuran ini akan lebih menghaluskan partikelpartikel yang masih kasar. Formula disaring kering, kemudian dilakukan pencampuran dengan air, agar didapatkan masa cair yang baik. Pencampuran air masing-masing formula glasir (biru kehijauan, coklat muda, merah muda, biru) dicampur dengan air sebanyak $150 \mathrm{cc}$, tetapi untuk formula glasir hijau muda dicampur dengan air $100 \mathrm{cc}$. Sedikit perbedaan penambahan air pada formula glasir hijau muda disebabkan formula tersebut relatif lebih mudah encer daripada formula glasir yang lain.

Formula glasir yang sudah diberi air kemudian disaring dengan menggunakan saringan khusus, tahap penyaringan basah ini menggunakan ukuran saringan sebesar 100 mesh, dengan maksud agar butiran glasir basah menjadi lebih halus dan tidak ada yang menggumpal. Masa glasir yang telah diberi air dan telah melewati tahap saring yang kedua dan siap untuk diaplikasikan pada lempeng biskuit sebagai media untuk eksperimen.

\section{Penerapan Lima macam warna glasir}

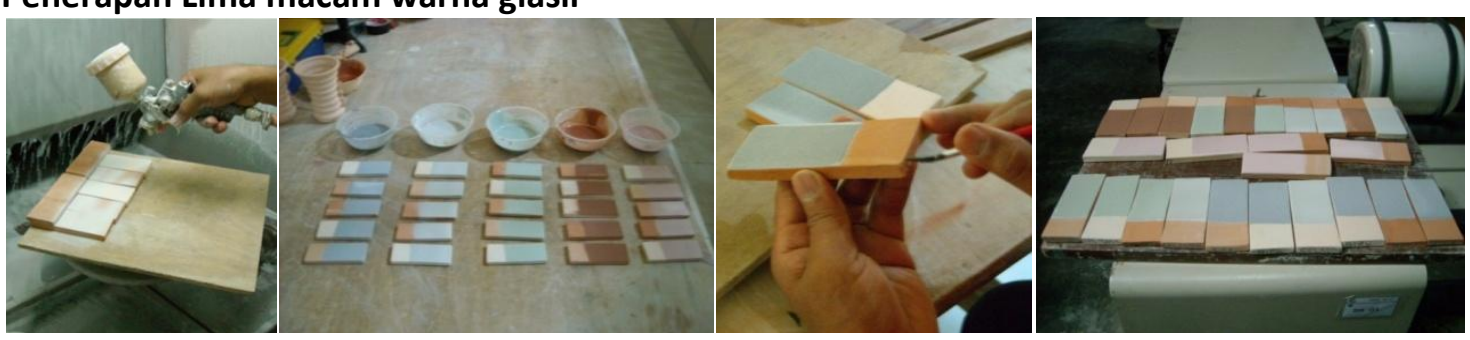

Gambar 9. Penyemprotan cairan glasir pada permukaan lempeng glasir

Tahapan proses eksperimen selanjutnya adalah dengan menyemprotkan cairan glasir di atas permukaan lempeng glasir. Penggunaan alat spray gun dengan kompresor akan lebih memudahkan proses aplikasi, dan dengan alat ini akan menghasilkan permukaan yang rata. Karakter tanah liat akan sangat mempengaruhi daya serap dari formula glasir yang sedang diaplikasikan pada permukaan lempeng eksperimen, kasus yang muncul dari eksperimen ini terjadi pada lempeng keramik yang menggunakan tanah liat Pacitan, karakter tanahnya yang sangat padat menyebabkan formula glasir sulit terserap. Setelah glasir rata disemprotkan pada semua lempeng eksperimen, kemudian mulai ke tahapan selanjutnya yakni pemberian kode pada sisi bawah lempeng eksperimen glasir.

\section{Pembakaran Glasir/ Bakar II}

Setelah semua proses aplikasi lima macam warna glasir selesai dilakukan kemudian menuju ke tahapan selanjutnya yaitu memulai pembakaran yang kedua, yakni proses pembakaran glasir hingga mencapai suhu $1200^{\circ} \mathrm{C}$ pembakaran tetap dengan pembakaran oksidasi.

\section{Hasil Eksperimen}

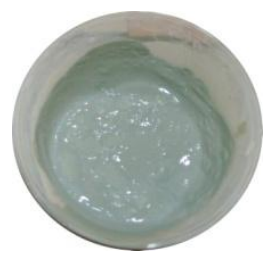

Gb. 10. Glasir mentah

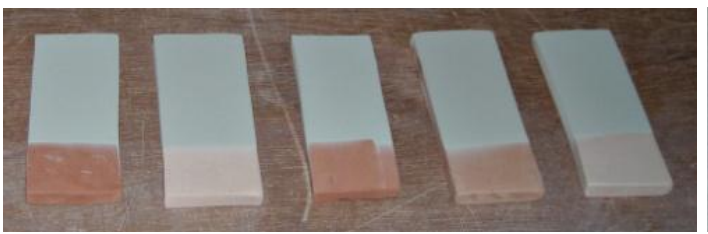

Gb. 11. Glasir yang telah diaplikasikan

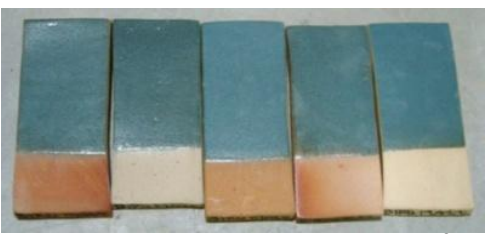

Gb. 12. Glasir setelah bibakar $1200^{\circ} \mathrm{C}$ 
Glasir biru kehijauan, glasir ini merupakan jenis glasir matt atau doff kandungan formulanya meliputi: Feldspar 47,5 gr; Whiting 18,6 gr; Kaolin 14,6 gr; Zinc oxide 13,4 gr; Kwarsa 5,9 gr; Cobalt oxide 0,5 gr; Chrome 1 gr. Glasir ini menjadi matt disebabkan kandungan whiting dalam formula yang tinggi, berdasarkan wawancara dengan Bapak Urip sebagai prakrisi glasir di P4TK Seni dan Budaya Yogyakarta, glasir matt merupakan glasir yang relatif stabil terhadap perubahan suhu di dalam tungku pembakaran sehingga karakter tanah liat yang memiliki karakter berbeda-beda tidak begitu mempengaruhi hasil warna glasir, walaupun warna glasir pada formula ini sedikit ada perbedaan antara satu dengan yang lain hal ini disebabkan karena adanya kandungan cobalt oxide di dalam formula, oksida ini termasuk oksida yang sangat peka terhadap tingkat kepadatan tanah serta perbedaan warna tanah, sifat tersebut dapat mempengaruhi walaupun tidak begitu signifikan. Perbedaan warna juga dapat muncul apabila bahan-bahan glasir di dapatkan dari daerah yang berbeda, dalam formula ini sebagai contoh kaolin menggunakan dari Wonosari, feldspar dari Malang, dan kwarsa dari malang.

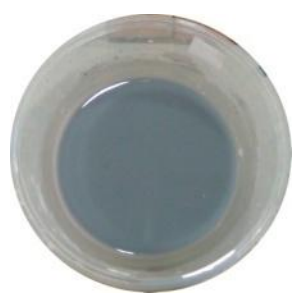

Gb. 13. Glasir mentah

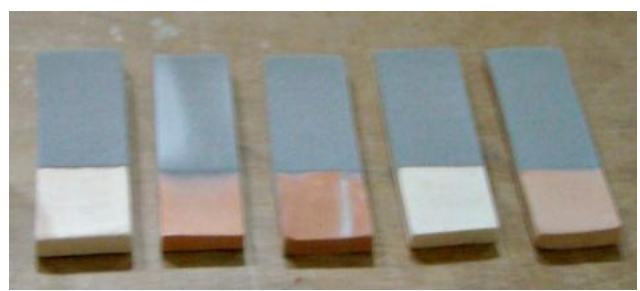

Gb. 14. Glasir yang telah diaplikasikan

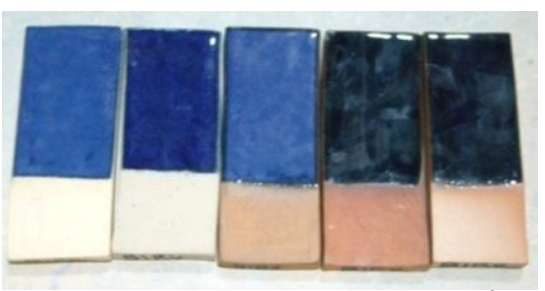

Gb. 15. Glasir setelah bibakar $1200^{\circ} \mathrm{C}$
Glasir biru glossy atau mengkilat, kandungan dari formula glasir ini adalah: TSG $100 \mathrm{gr}$; Zircon $15 \mathrm{gr}$; Cobalt oxide $3 \mathrm{gr}$. Formula glasir biru ini merupakan formula yang paling tidak stabil, hal ini dapat terlihat pada hasil bakar glasir pada warna tanah yang cerah glasir biru akan muncul dengan baik walaupun tetap ada perbedaan tingkat warnanya, akan tetapi untuk karakter tanah yang memiliki warna gelap warna glasir biru menjadi biru kehitaman.

Formula glasir ini merupakan formula yang cukup sederhana, menggunakan glasir jadi yang berupa glasir TSG dan kemudian ditambahkan dua buah oksida yakni zircon dan cobalt, seperti telah disinggung pada formula glasir yang pertama bahwa oksida cobalt merupakan oksida yang sangat peka, Ambar Astuti menyatakan bahwa kandungan oksida cobalt dalam jumlah yang kecil memberi warna biru, tetapi dalam jumlah yang agak besar memberi warna hitam.

Formula glasir ini menggunakan oksida cobalt sebanyak $3 \mathrm{gr}$, hal ini dapat juga merupakan sabagai sebab mengapa ada sebagian warna biru menjadi biru kehitaman, tetapi kemudian muncul pertanyaan mengapa ada yang berwarna biru sempurna. Pertanyaan tersebut dapat dijawab dengan mengamati karakter tanah liatnya, karakter tanah liat yang berwarna gelap, warna biru menjadi biru kehitaman tetapi untuk tanah liat yang berwarna cerah dan cenderung putih warna biru akan muncul sempurna.

Hal tersebut akan lebih jelas bahwa warna tanah yang cenderung gelap memiliki kandungan oksida besi yang lebih tinggi sehingga akan sangat mempengaruhi hasil bakar formula glasir, sehingga apabila pengrajin atau seniman yang menggunakan bahan tanah liat yang berwarna gelap dalam pembuatan produk atau karyanya ingin 
mendapatkan warna glasir yang cemerlang dapat mensiasati dengan memberikan lapisan tanah liat yang berwarna cerah pada badan keramik yang berwarna gelap sebelum formula glasir diaplikasikan. Alternatif yang lain adalah dengan cara menurunkan kandungan oksida yang sangat peka dengan karakter tanah menjadi lebih sedikit dari persentase yang biasa digunakan.

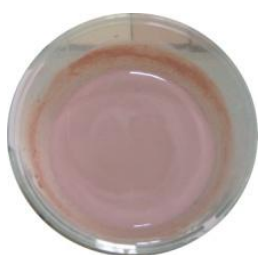

Gb. 16. Glasir mentah

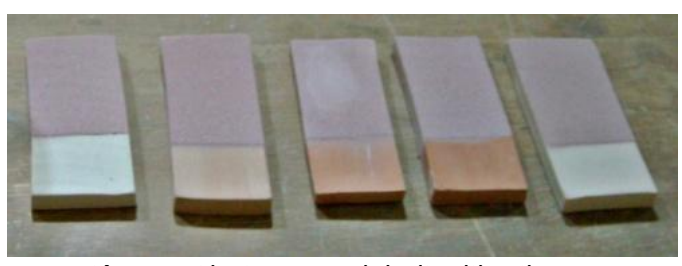

Gb. 17. Glasir yang telah diaplikasikan

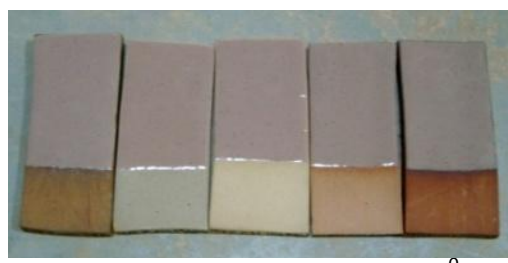

Gb. 18. Glasir setelah bibakar $1200^{\circ} \mathrm{C}$
Formula glasir merah muda / pink ini memiliki kandungan yang cukup sederhana yakni: Glasir TSG $100 \mathrm{gr}$; oksida zircon $15 \mathrm{gr}$; stain merah maron $6 \mathrm{gr}$. Formula ini menggunakan glasir jadi yang berupa glasir jadi TSG dan kemudian ditambahkan satu buah oksida dan satu buah stain atau pigment glasir yakni oksida zircon dan stain merah maroon.

Hasil bakar dari formula glasir ini dapat dikatakan sangat stabil dan tidak banyak perbedaan warna walaupun terjadi perbedaan karakter tanah liat baik sifat maupun warnanya, apabila dilihat dalam gambar warna dalam kondisi mentah dan setelah melalui bakar glasir tidak banyak mengalami perubahan. Perubahan hanya terjadi dikarenakan glasir mencair dan berubah menjadi mengkilat, hal ini disebabkan jenis formula glasir ini merupakan glasir yang berkarakter mengkilap atau glossy.

Penggabungan antara stain dan oksida menjadikan warna dalam formula ini menjadi sangat stabil dan secara jelas warna glasir sudah terlihat pada saat masih mentah atau cair. Hal ini sangat menguntungkan bagi pengrajin atau seniman yang akan mengaplikasikan glasir pada karya atau produknya sehingga seniman tidak begitu mencemaskan hasil warna yang akan muncul setelah melalui proses pembakaran.

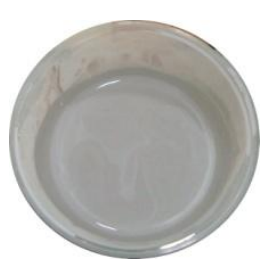

Gb. 19. Glasir mentah

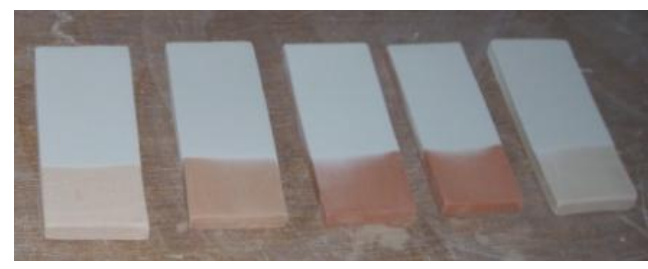

Gb. 20. Glasir yang telah diaplikasikan

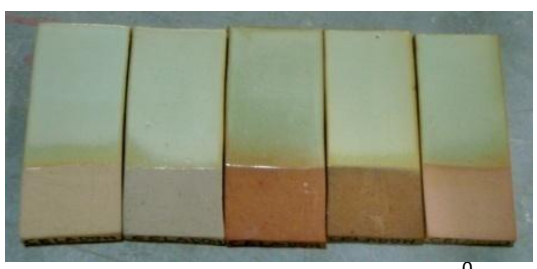

Gb. 21. Glasir setelah bibakar $1200^{\circ} \mathrm{C}$
Glasir hijau muda ini merupakan glasir matt, dengan kandungan formulanya sebagai berikut: Glasir opag $100 \mathrm{gr}$; oksida titanium 20 gr; zinc oxide $8 \mathrm{gr}$; Barium 1,5 gr; Copper oxide $2,5 \mathrm{gr}$. Glasir ini merupakan glasir yang sangat berbeda antara warna basah dan setelah bakar hal tersebut dapat terlihat pada gambar, tampilan warna yang dihasilkan tidak begitu jauh berbeda antara karakter tanah satu dengan yang lain, dari keterangan yang terdahulu sudah diterangkan bahwa glasir matt merupakan glasir yang relatif stabil.

Tingkat kestabilan formula glasir akan sangat terasa jika hasil dari formula glasir tersebut telah mengalami proses 
pembakaran. Warna hijau yang muncul didapatkan dari kandungan copper oxide, sedang oksida yang lain akan mendukung tingkat kestabilan warna dan munculnya karakter warna hijau yang dikehendaki oksida titanium akan memunculkan warna putih crem, penambahan barium oksida memberikan efek matt dari glasir ini.

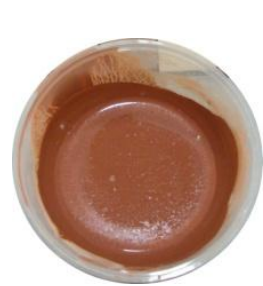

Gb. 22. Glasir mentah

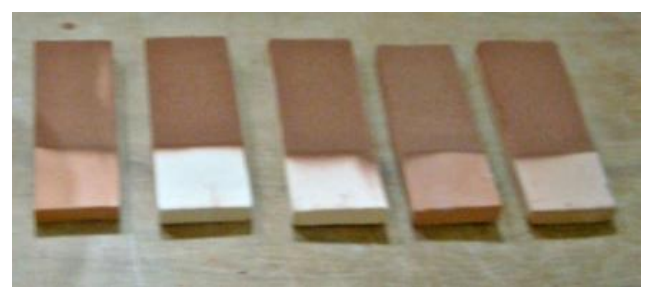

Gb. 23. Glasir yang telah diaplikasikan

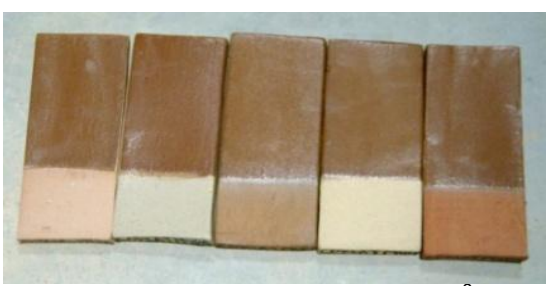

Gb. 24. Glasir setelah bibakar $1200^{\circ} \mathrm{C}$
Glasir ini memiliki komposisi: Feldspar 47,5 gr; Whiting 18,6 gr; Kaolin 14,6 gr; Zinc oxide 13,4 gr; Kwarsa 5,9 gr; Fe 15 gr. Kaolin dalam komposisi glasir ini didapatkan dari Wonosari, feldspar dari Malang dan kwarsa juga dari Malang, komposisi glasir ini merupakan perpaduan murni jadi tidak menggunakan glasir dasar seperti pada formula glasir yang lain.

Karakter glasir ini juga memiliki warna yang tidak jauh berbeda antara warna basah dan warna setelah dilakukan pembakaran glasir. Karakter tanah liat tidak begitu berpengaruh terhadap komposisi glasir jenis ini, sebab glasir formula glasir ini bersifat menutup, jadi warna tanah relatif tidak begitu berpengaruh. Warna tanah dalam eksperimen ini secara keseluruhan tidak begitu berubah, hanya tanah pacitan yang menjadi semakin cerah apabila dibandingkan dengan warna tanah pada waktu masih basah.

\section{Kesimpulan}

Faktor-faktor yang mempengaruhi ketepatan warna glasir adalah cara pembakaran mengunakan reduksi atau oksidasi dan tercapainya suhu bakar glasir dan ketepatan penimbangan komposisi glasir, selain hal tersebut ketepatan juga ditentukan jenis glasir yang digunakan apabila menggunakan glasir glossy penggunaan karakter tanah liat yang berwarna cerah akan lebih mudah dalam pencapaian warna yang diinginkan khususnya apabila menggunakan oksida cobalt dan fe, ketepatan juga dapat dicapai adanya komposisi pewarna glasir yang dikombinasikan antara oksida dengan stain atau pigment glasir. Kombinasi tersebut dapat membuat formula glasir lebih stabil saat melewati proses pembakaran.

Karakter tanah liat relatif mempengaruhi kemunculan warna glasir hal ini disebabkan kandungan oksida yang tinggi pada tanah liat yang memiliki warna gelap sehingga oksida tersebut dapat bereaksi terhadap lapisan glasir yang telah diaplikasikan. Karakter tanah liat relatif tidak berpengaruh terhadap kemunculan warna jika menggunakan glasir yang berbasis matt atau tidak mengkilap dengan kandungan whiting atau barium yang agak tinggi.

Warna glasir akan muncul sesuai dengan keinginan seniman atau pengrajin apabila cara mengglasir dilakukan sesuai prosedur dengan penyaringan yang halus dan masa selalu dalam keadaan teraduk rata sehingga tidak ada pengendapan komposisi yang masanya lebih berat. Penggunaan tanah dengan karakter yang cerah akan lebih baik dalam mencapai tingkat keberhasilan kemunculan warna glasir sesuai dengan rencana. Apabila karakter tanah liat yang digunakan dalam pembuatan produk berwarna gelap, dapat disiasati dengan melapisi badan keramik dengan jenis tanah liat yang berwarna cerah. 
Sebuah komposisi kimia akan menjadi lebih jelas dan dimengerti reaksi dan hasilnya jika dilakukan sebuah eksperimen, jadi dalam keramik apabila ingin merencanakan tujuan komposisi glasir yang baru dengan warna yang baru harus dilakukan eksperimen warna glasir dan tanah liat yang akan dipergunakan untuk membuat karya maupun produknya secara massal.

\section{Daftar Pustaka}

Astuti, Ambar, Pengetahuan Keramik. Yogyakarta. Gadjah Mada University Press. 1997.

Atmaja, Mochtar Kusuma, Perjalanan Seni Rupa Indonesia, Bandung, Panitia Pameran KIAS: 1991.

Dharsono, Estetika. Bandung. Rekayasa Sains: 2007.

Daly, Greg, Glazes and Glazing Techniques, Australia. Kangaroo Press. 1995.

Razak, R.A. Industri keramik. Jakarta. Balai Pustaka, 1993.

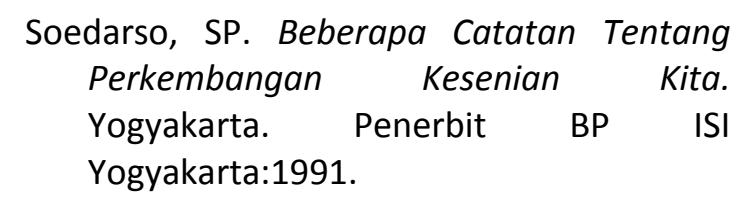

